\title{
UMA PROPOSTA DE ATENDIMENTO ÀS NECESSIDADES DE INFORMAÇÃO DOS USUÁRIOS DA BIBLIOTECA ESCOLAR POR MEIO DO BENCHMARKING E DO SENSEMAKING
}

\author{
UNA PROPUESTA DE ASISTENCIA A LAS NECESIDADES DE \\ INFORMACIÓN DE LOS USUARIOS DE LA BIBLIOTECA \\ ESCOLAR POR MEDIO DEL BENCHMARKING Y DEL \\ SENSEMAKING
}

\begin{abstract}
Ariel Behr - behr.ariel@gmail.com Doutorando em Administração(PPGA/EA/UFRGS).

Eliane Lourdes da Silva Moro - eliane_moro@yahoo.com.br Doutoranda em Educação (PPGEDU/UFRGS). Professora do Curso de Blblioteconomia da FABICO/UFRGS.

Lizandra Brasil Estabel - liz.estabel@gmail.com Doutora em Informática na Educação. Docente do Instituto Federal do Rio Grande do Sul (IFRS) e do Curso de Especialização em Bibliotecas Escolares e Acessibilidade (EBEA/FABICO/UFRGS).
\end{abstract}

\begin{abstract}
Resumo
Este artigo apresenta uma proposta de discussão a respeito da qualidade nos serviços de informação, a construção do conhecimento focada no usuário e considerações acerca da utilização da comparação de informações na busca por excelência. Aborda os processos de busca, tratamento, utilização e comparação de informações para a verificação da qualidade dos serviços prestados aos usuários das bibliotecas, enfocando a aplicação de benchmarking e do sensemaking para qualificar os serviços das bibliotecas e atender aos usuários nas suas necessidades de busca da informação. Caracteriza-se como uma contribuição aos bibliotecários, possibilitando uma reflexão a respeito da necessidade de novas atitudes, que incluam a interação com os usuários na verificação do processo de busca de informação no espaço da biblioteca, na interpretação do sentido, na construção do conhecimento e na tomada de decisão a fim de tornar os serviços de informação qualificados e acessíveis para todos.
\end{abstract}

\section{Palavras-chave}

Busca de Informação. Qualidade nos Serviços de Informação. Gestão de Bibliotecas. 


\section{INTRODUÇÃO}

O advento da Sociedade da Informação e do Conhecimento, e o domínio das Tecnologias de Informação e de Comunicação (TICs) transformaram o universo das bibliotecas e serviços de informação. Inicialmente, o desenvolvimento de coleções das bibliotecas estava mais focado na quantidade de itens que o compunham do que especificamente em sua qualidade. Porém, nos dias atuais, as bibliotecas e serviços de informação são avaliados em relação aos serviços que prestam e aos produtos que oferecem, sendo considerado não somente o acervo, mas também as TICs disponíveis e o uso decorrente das mesmas.

É indiscutível a necessidade dos bibliotecários, e dos gestores de informação em geral, de utilizarem instrumentos de avaliação dos serviços prestados, que possam prover elementos para fundamentar decisões, planejar, analisar, avaliar e oferecer serviços que atendam às necessidades informacionais dos usuários. E a qualidade dos serviços bibliotecários deve confirmar, de forma consistente, as necessidades que levaram o usuário a procurá-lo, baseando-se na percepção e nas expectativas que o mesmo apresenta em relação ao processo de busca de informação e à prestação dos demais serviços.

Neste contexto, a biblioteca escolar aparece como um ambiente de aprendizagem e de construção do conhecimento que deve propiciar ao usuário ser o objeto do serviço. Este ideal permite a participação e a colaboração, o que ao cabo contribui para a qualidade dos sistemas de informação, por se tornarem estes mais flexíveis e adaptáveis às necessidades destes usuários. Nesta idéia, a biblioteca se transforma em um espaço democrático e personalizado, com serviços de qualidade, que buscam a satisfação do usuário, sendo este alguém que se integra ao espaço e cria vínculos permanentes.

Envolto nesta realidade, o objetivo deste artigo está em discutir a qualidade nos serviços de informação prestados pelas bibliotecas escolares, considerando a construção do conhecimento focada no usuário e a utilização da comparação de informações na busca por excelência. Para tanto são feitas considerações sobre a busca, o processamento e o tratamento da informação, por meio do sensemaking enquanto forma de conhecer o usuário e suas necessidades.

Entende-se que os profissionais que atuam nas bibliotecas são partícipes do processo de aprendizagem e construção de novos significados que se efetivam a cada momento do desenvolvimento humano. E por esta razão, observa-se que a relevância deste artigo está na contribuição a estes profissionais, possibilitando uma reflexão sobre a 
necessidade de novas atitudes neste local em que o fluxo de informações é constante, e onde as necessidades humanas permeiam cada ciclo de busca de informação.

\section{O USUÁRIO NA BUSCA DA INFORMAÇÃO}

O bibliotecário como gestor de informação, deve ter consciência de que, quando o usuário procura a biblioteca na busca por informação, deve estar pronto e apto para auxiliá-lo percebendo o que ele realmente procura. No contexto da biblioteca escolar, é comum que o usuário não saiba ou não consiga expressar o que está querendo, entrando aí a função mais importante do bibliotecário: perceber e propiciar a informação de forma correta ao usuário, de modo a satisfazer as suas necessidades de busca.

Grogan (2001) afirma que na busca da informação, em diferentes situações, o mesmo consulente pode querer: uma fonte de informação, instrução sobre o uso de uma fonte de informação ou mensagens colhidas numa fonte de informação; ou também diferentes consulentes com a mesma consulta podem querer respostas diferentes. Além disso, "o nível de serviço e o tipo de informação que satisfazem a um cliente talvez não sejam aquilo que, na mensagem inicial, ele expressou, de forma imperfeita, como sendo a sua necessidade" (GROGAN, 2001, p.22). Os usuários sentem a necessidade de conhecer e de compreender, por isso

se os bibliotecários de referência se empenhassem em lembrar constantemente a si próprios o que estão fazendo não é simplesmente fornecer informações, mas atender a essas necessidades cognitivas, isso serviria para neutralizar uma tendência, amiúde censurada, de que parecem dar mais atenção à consulta do que ao consulente (GROGAN, 2001, p.22).

O início do processo de busca da informação está então em identificar a necessidade do usuário. Abraham Harold Maslow, psicólogo americano, formulou na primeira edição do livro Motivation and Personality, em 1954, uma teoria da motivação apresentando as necessidades humanas organizadas em níveis, representadas usualmente numa pirâmide (Figura 1) que englobam três tipos de motivos: físicos, de interação com os outros e com o self. 


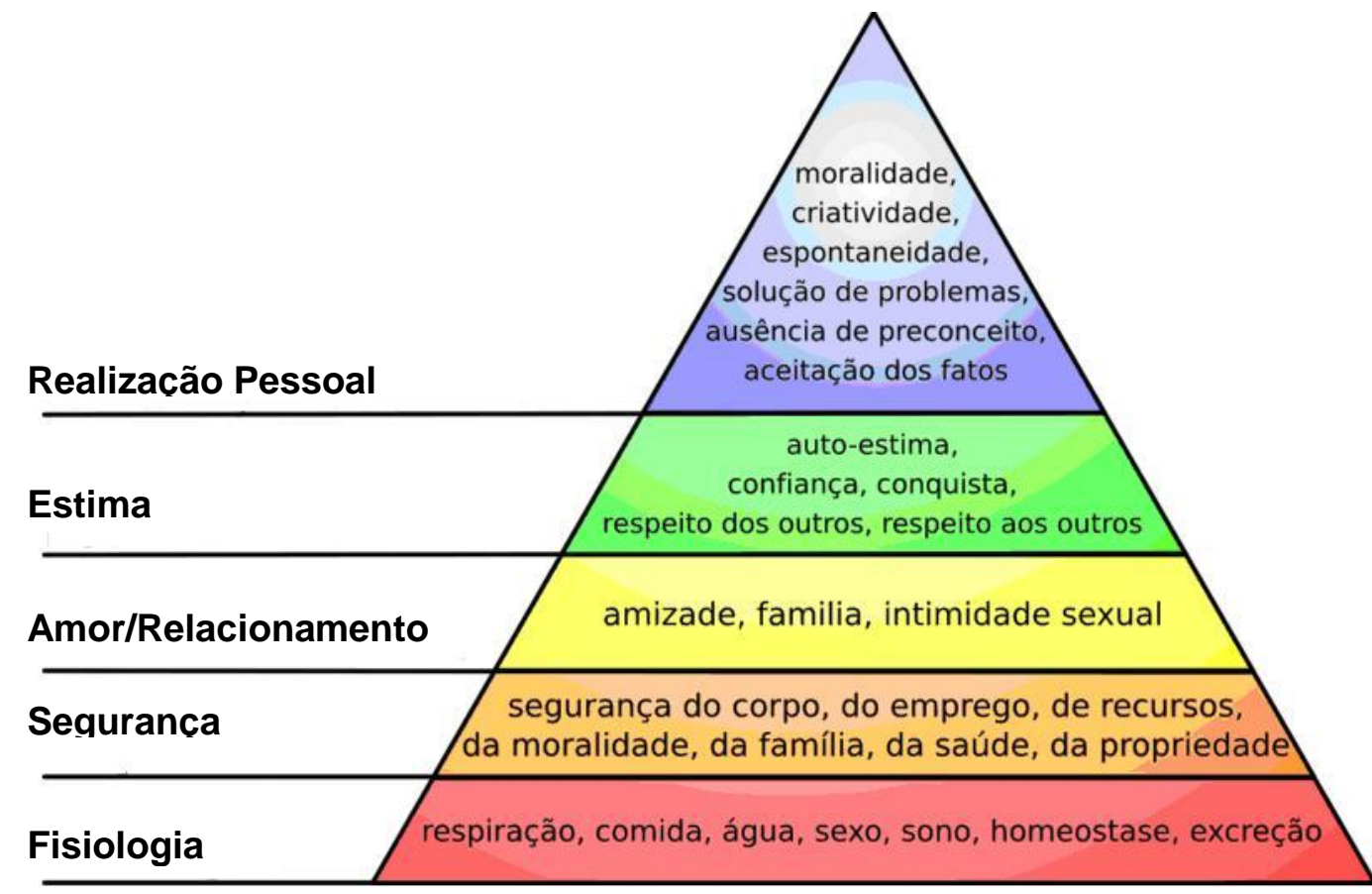

Figura 1 - Hierarquia das Necessidades

Fonte - adaptado de MASLOW (1970)

Pensemos então na motivação de nosso usuário quando procura os serviços da biblioteca e quais seriam suas necessidades de informação. Lira et al. (2007) propõem e descrevem os estágios do processo de decisão do uso da informação entendidos nos seguintes estágios:

\section{Estágio: reconhecimento da necessidade do uso da informação}

O usuário iniciará seu processo de alcance da informação por esta etapa onde deverá, primeiramente, sentir que existe uma diferença entre o estado desejado e a situação real das coisas. Este sentimento de falta deve ser suficientemente forte para despertar no usuário a busca pela informação, podendo esta situação ocorrer por conta do usuário, quando este se sente desconfortável em determinado assunto, ou pode ser estimulado pelo ambiente em que se insere. A motivação também pode vir por conta de razões profissionais quando, por exemplo, existe a possibilidade de assumir novas responsabilidades, conhecer e usar TICs, agregar valor aos serviços prestados, entre outros.

\section{2을 Estágio: a busca de informações}

O usuário busca a informação na tentativa de desfazer a lacuna existente em seu conhecimento, mas acima de tudo, para satisfazer uma necessidade ou solucionar um problema. Quanto maior for o envolvimento do usuário com a solução de um problema, maior será seu esforço na busca da informação necessária. As 
fontes para busca são diversas e a biblioteca é mais uma delas e, talvez, seja a mais formal de todas. Neste sentido Choo (2003) assevera que a falta de informação pode ser sanada através de conversas com outras pessoas, observações e reflexões, até que o indivíduo seja capaz de expressar na forma narrativa ou escrita a sua necessidade.

\section{3ํEstágio: a decisão de uso da informação}

Neste momento o usuário escolhe qual a informação trará melhores resultados a sua busca. Ou seja, selecionará as informações coletadas a fim de reter somente as que atendam suas necessidades. Neste momento o usuário criará critérios para selecionar a informação segundo a importância de cada assunto para sua compreensão. Fatores como a qualidade, a confiabilidade e a facilidade na obtenção da informação são decisivas neste momento.

\section{Estágio: avaliação pós - uso da informação}

O processo não se encerra no momento da obtenção da informação, pois ainda deve-se levar em conta a influência da utilização por parte do usuário. Sua satisfação será decorrente do desempenho desta informação na realidade do usuário, ou seja, fatores como a clareza, a relevância e a atualização da informação farão com que sejam satisfeitas as necessidades ou não. Quando o usuário fica satisfeito com o resultado obtido tem maior probabilidade de compartilhar e propagar a informação, possibilitando a transformação desta em conhecimento. E da mesma maneira, resultados negativos podem contar com a aversão deste usuário à informação e ao seu canal de veiculação.

Analisando estes estágios, fica evidente que não existe um fim para este processo, uma vez que novas necessidades surgirão ou poderão ser propostas ao usuário; e os meandros deste fluxo são direcionadores fundamentais da nova necessidade que pode surgir.

Outro enfoque de uso da informação é proposto por Choo (2003) que enxerga este fluxo em três arenas, que funcionam como processos interligados, se complementando e alimentando mutuamente através de uma visão holística do uso da informação; e podem ser entendidos da seguinte forma: 


\section{1a arena: criar significado}

O principal processo do uso da informação é a interpretação de notícias como sentido/significado às mudanças externas do ambiente. A informação relevante deve ser indicada e discutida pelo grupo, ou pelo indivíduo, para que se chegue a uma interpretação consensual.

\section{$2^{\mathrm{a}}$ arena: construir conhecimento}

O principal momento no uso da informação está na "conversão do conhecimento", que ocorre através do diálogo discursivo em que os membros compartilham e articulam seus conhecimentos e convertem a informação levando à inovação na forma de "novos produtos ou novas competências" (CHOO, 2003, p.50).

\section{$3^{\mathrm{a}}$ arena: tomar decisões}

Neste momento o processo de tomada de decisão é analisado e são avaliadas as alternativas disponíveis, que se apresentam como vantagens ou desvantagens, onde regras, rotinas e preferências orientam a busca da informação e a avaliação das alternativas.

Para o autor, no contexto organizacional é possível observar três modos de uso da informação - interpretação, conversão e processamento - que são processos sociais dinâmicos, e continuamente constituem e reconstituem significados, conhecimentos e ações. Portanto, organização do conhecimento, neste meio, significa a capacidade de integrar eficientemente os processos de criação de significado, construção do conhecimento e tomada de decisões (CHOO, 2003), o que pode ser mais bem compreendido e ilustrado através da Figura 2. 


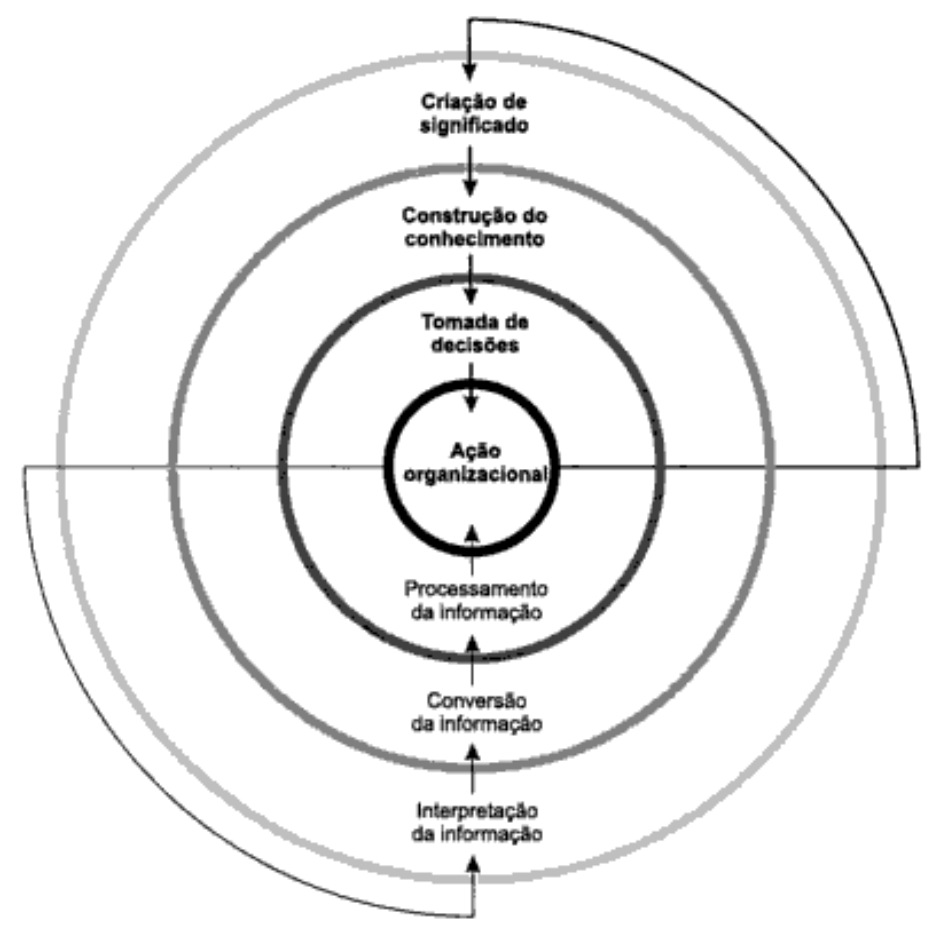

Figura 2 - Esquema da organização do conhecimento Fonte - CHOO (2003, p.31).

Outra abordagem ainda é a de Grogan (2001) que estabelece uma seqüência lógica para o entendimento das etapas que considera decisórias no processo essencial de comunicação interpessoal entre bibliotecário e usuário, com a finalidade específica de satisfazer necessidades de informação. Para explicitar esse processo, apresenta oito passos, da seguinte forma:

\section{1ํ passo: o problema}

Todo usuário ao chegar à biblioteca traz consigo um problema que pode ser intrapsicológio (interno; interação com o self) ou inter-psicológico (externo; interação com o meio). Cabe ao bibliotecário estar ciente que a identificação deste problema é o ponto inicial da boa prestação de seu serviço.

\section{2o passo: a necessidade de informação}

Caracteriza-se no processo de busca da solução para o problema vivenciado. A necessidade de informação pode se apresentar como vaga e imprecisa, sem estar formada e com dificuldade de ser expressa e percebida.

\section{3o passo: a questão inicial}

A questão inicial surge sempre através de uma pergunta, ou na identificação de uma lacuna. A formulação se origina no intra-pessoal como uma espécie de "en- 
saio mental" antecipando o encontro "inter-pessoal" no momento da apresentação da questão para o outro, quando ocorre a interação entre usuário e bibliotecário.

\section{4ำ passo: a questão negociada}

A questão negociada exige frequentemente, uma "redefinição ou reformulação" que possibilite um cotejo mais adequado com a terminologia e a estrutura das fontes de informação disponíveis e acessíveis na biblioteca.

\section{5ำ passo: estratégias de busca}

Este passo se caracteriza com procedimentos calcados nas questões e decisões. A primeira decisão está na maneira como o acervo de informações, seja ele local ou remoto, será consultado referindo-se a uma análise minuciosa do tema da questão, identificando seus conceitos e suas relações traduzidos na linguagem apropriada de busca e de acesso da informação; a segunda decisão será calcada na questão em "qual de suas partes será consultada, e em que ordem. Implica na escolha de vários caminhos possíveis para a busca, seleção e acesso à informação.

\section{6ำ passo: o processo de busca}

A estratégia de busca deverá ser flexível para que permita ao processo de busca uma mudança de percurso, caso seja necessário.

\section{$7^{\circ}$ passo: a resposta}

A resposta não constitui a finalização do processo, pois recém o consulente terá chegado ao resultado da busca. Quando a resposta for positiva, responderá às necessidades iniciais de busca do usuário, mas se a busca tiver um resultado negativo, torna-se desagradável a resposta, e não terá suas necessidades satisfeitas.

\section{8ำ passo: a solução}

Para o autor, "uma resposta é somente uma solução potencial" (GROGAN, 2001, p.54). Portanto, neste passo é importante a interação entre bibliotecário e usuário na avaliação do 'produto da pesquisa', onde o resultado da busca é aprovado por ambos, para que se considere o processo concluído.

No entanto, na concepção dos autores deste artigo, ainda existiria um passo final no processo apresentado, que se caracteriza na avaliação dos resultados, isto é, na verifica- 
ção se a necessidade inicial de busca da informação e do problema apresentado pelo usuário foi satisfeito ou resolvido.

Durante o processo de busca é comum que o bibliotecário se depare com a vulnerabilidade do usuário, uma vez que ele está aberto para receber informações e disposto a entendê-las. Neste momento o bibliotecário deve também estar aberto para entender o usuário e não somente despejar materiais sobre o mesmo. Esta é uma oportunidade muito importante para que o usuário conheça a biblioteca como sendo um local onde seus problemas são minimizados e não agravados.

Logo, é vital que o mediador deste processo de busca conheça os caminhos que a informação percorre no usuário para que possa agir como facilitador neste processo. Tendo em mente cada etapa deste processo, pode-se então traçar estratégias e atuar com maior eficiência, promovendo a satisfação do usuário, e assim reforçando a importância e a necessidade da biblioteca.

\section{QUALIDADE EM SERVIÇOS DE INFORMAÇÃO}

Quando se aborda a qualidade do serviço de informação o primeiro aspecto a ser considerado é que o objeto de análise trata-se de um serviço, e isto remete a algumas premissas que se deve conhecer. MacDonald (1994 apud VERGUEIRO, 2002) ${ }^{1}$ mostra no Quadro 1, algumas diferenças presentes na comparação entre a qualidade de um serviço e de um produto.

\section{PRODUTO}

O cliente recebe um produto tangível na forma de bens que podem ser vistos e tocados

Os bens permanecem com o cliente

A produção e entrega dos bens são normalmente separados

Poucos produtores têm contato com os clientes

O cliente raramente se evolve na produção

Os bens podem ser objeto de serviço posterior de conserto e reparação

Os bens podem ser objeto de garantia, mas o produtor tem maior oportunidade para atenuar os efeitos no cliente e assim

\section{SERVIÇO}

O cliente recebe um serviço intangível que pode satisfazê-lo ou não

Os serviços são consumidos no momento de seu fornecimento

A produção, entrega e consumo ocorrem freqüentemente ao mesmo tempo

A maioria dos produtores tem contato com os clientes

O cliente é freqüentemente envolvido nos serviços

Os serviços já foram consumidos e não podem ser reparados

É difícil refazer os serviços que não atendem aos requisitos - o impacto financeiro é normalmente total

\footnotetext{
${ }^{1}$ MacDONALD, John. Service is different. TQM Magazine, v.6, n. 1, p.5-7, 1994 apud VERGUEIRO, Waldomiro. Qualidade em Serviços de Informação.
} 


\begin{tabular}{|l|l|}
\hline diminuir a penalidade financeira & \\
\hline $\begin{array}{l}\text { Os bens podem ser comprados para ser } \\
\text { armazenados de modo a satisfazer as ne- } \\
\text { cessidades do cliente }\end{array}$ & $\begin{array}{l}\text { Os serviços não podem ser armazenados, } \\
\text { mas podem ainda estar disponíveis para a } \\
\text { demanda do cliente }\end{array}$ \\
\hline $\begin{array}{l}\text { Os bens podem ser transportados para o o } \\
\text { ponto de venda }\end{array}$ & $\begin{array}{l}\text { Alguns serviços são transportáveis, mas a } \\
\text { maioria requer o transporte do provedor do } \\
\text { serviço }\end{array}$ \\
\hline $\begin{array}{l}\text { É relativamente fácil para os clientes ava- } \\
\text { liar a qualidade dos bens }\end{array}$ & $\begin{array}{l}\text { A qualidade do serviço depende mais da } \\
\text { percepção subjetiva e da expectativa }\end{array}$ \\
\hline $\begin{array}{l}\text { Com freqüência, os bens são tecnicamente } \\
\text { complexos - o cliente sente-se mais de- } \\
\text { pendente do produtor }\end{array}$ & $\begin{array}{l}\text { Os serviços parecem menos complexos - o } \\
\text { cliente sente-se qualificado para argumen- } \\
\text { tar com o fornecedor }\end{array}$ \\
\hline
\end{tabular}

Quadro 1 - Diferenças entre produtos e serviços

Fonte - adaptado de VERGUEIRO (2002, p.38).

Estas diferenças fazem da prestação do serviço um trabalho muito criterioso e repleto de pontos que merecem atenção. É importante verificar que no momento em que o serviço é prestado em contato direto com o cliente, este se torna algo muito particular e por isso deve atender pontualmente às necessidades de um sujeito em especial. Opostamente, um produto, por ser algo 'empacotado', admite a padronização das características, assim tendo o sujeito que se adaptar ao produto. Mas existe o ponto coincidente onde 0 produto ou serviço que atender ao maior número de necessidades, com eficiência e qualidade, será o preferido pelo usuário.

São diversas as faces da determinação da qualidade de um serviço. Pode-se dizer que a primeira e fundamental, é que seja quem for que preste um serviço, deve ter a capacidade e a competência para bem cumprir sua tarefa. Outra característica na relação da prestação do serviço está em transmitir ao usuário a segurança necessária para que ele seja atendido da melhor maneira possível. A confiança é o fator decisivo na escolha de um prestador de serviço, pois uma vez que o usuário confie que terá sua necessidade entregue a um profissional aberto e capaz, existirão as melhores condições para que tudo seja feito.

Depois disso, ainda precisa o prestador ter em mente que sua disponibilidade, apresentação e comunicação são meios percorridos pelo cliente para the eleger, sendo assim, são elementos que fazem parte de seu negócio. Exemplificando, pode-se pensar em uma vídeolocadora, com serviço de entrega e busca de filmes a domicílio, aonde temos diversas unidades dos filmes mais procurados, em um ambiente amplo e limpo, e com atendimento disponível e disposto a conhecer o cliente para melhor auxiliá-lo e servi-lo, além do horário de atendimento condizente com a disponibilidade dos clientes e serviços prestados pela internet. Este ambiente criado é o melhor convite e a melhor propaganda para quem "compra" um serviço. 
Ao se realizar um comparativo de serviços prestados entre esta vídeolocadora e uma biblioteca poder-se-ia pensar nas seguintes questões: A biblioteca é próxima do ambiente cotidiano de seus usuários? Oferece serviço de empréstimo com entrega e busca domiciliar? O acervo é atualizado, diversificado e está disponível? O espaço físico é adequado, prazeroso e acessível? $\mathrm{O}$ atendimento é personalizado e qualificado? O horário de funcionamento é condizente com a disponibilidade de freqüência dos usuários? Possui e disponibiliza recursos de internet?

Estas são indagações meramente especulativas, mas que servem como referência para a noção da qualidade do que se está oferecendo. Apresenta-se a seguir então, uma forma mais simples e confiável de conhecer as possibilidades de melhorar um 'negócio'.

\section{BENCHMARKING}

Fazendo uma nova analogia, não é raro ouvir o caso onde tudo corria bem em uma empresa líder de mercado, e de repente, a concorrência começa a se aproximar, mas os gestores acreditam muito na qualidade de seu produto e, por isso, perdem cada vez mais mercado, dinheiro, motivação e todos os gráficos passam a indicar a decadência do negócio.

Seja qual for o meio, a leitura do mercado é fundamental. O gestor tem a obrigação de identificar as falhas e as oportunidades de melhoria em seus processos, e ainda as oportunidades de avanço e retraimento no mercado. Não é nada muito complexo, basta conhecer bem o produto, o mercado e ter consciência de que a concorrência existe.

A técnica do benchmarking é simples e altamente eficaz, podendo ser traduzido seu significado para 'referencial comparativo', e consiste em ter, para cada atividade, um alvo ou uma fonte de comparação, ou seja, benchmarking nada mais é do que identificar boas práticas.

A empresa citada anteriormente era líder do mercado, mas poderia ter em mente que 'nunca é bom se comparar com quem está atrás, certo'? Errado! Com certeza esta empresa líder que perdeu mercado foi por que parou de olhar, tanto para a concorrência, quanto para o mercado, como para si mesma. Não há nada de mal em estabelecer um benchmarking dentro da própria empresa, como também nas atividades que a concorrência faz melhor ou até em uma empresa de outro setor. O que realmente importa é saber que sempre é possível dar um passo à frente. 
Como outro exemplo pode-se pensar em uma loja de chocolates, onde freqüentam muitos clientes e seus funcionários estão motivados. Os chocolates têm qualidade, mas o gestor quer um "algo a mais" em seu produto, assim escolhe investir na embalagem. Neste caso, será um hábito muito salutar se a empresa verificar como as perfumarias, sapatarias, lojas de roupas, entre outras, fazem seus pacotes. Seu referencial pode ser na loja de sapatos ou em outra loja de chocolates, mas a empresa tem alguém com que se comparar e um alvo a acertar.

Nos serviços o conceito é utilizado da mesma maneira, a diferença está em que a busca pela melhoria não está em algo físico, mas sim na qualificação do profissional, para que ele preste um melhor serviço. Pode-se comparar o serviço da biblioteca com outras bibliotecas, isso seria ideal, mas pode-se ter este benchmarking em outros serviços, por exemplo, pode-se comparar "o sistema de busca de livros" com o sistema daquela vídeolocadora. Enfim, não se deve deixar travar ao primeiro obstáculo. Os benchmarkings podem ser encontrados em uma pesquisa de mercado, em um questionário direcionado, em jornais e revistas, na literatura e em diversas outras fontes, mas para o caso especial das bibliotecas, aborda-se agora dois sites especializados na área biblioteconômica, indicados por Melo (2007), quais sejam:

\subsection{LibEcon}

O LibEcon é um site com benchmarking internacional de bibliotecas de diversos setores, que são parametrizados de acordo com o país e a economia do mesmo. O site é financiado pelo Institute of Public Finance e pela Comissão Européia e segue as normas internacionais ISO 2789 e ISO 11620 (indicadores de desempenho da biblioteca).

A seguir está um exemplo (Figura 3) dos dados encontrados através do histograma que traduz o tamanho das coleções existentes nas bibliotecas do país, numa proporção para cada mil usuários, comparando os países descritos com resultados mundiais e da comunidade européia. 


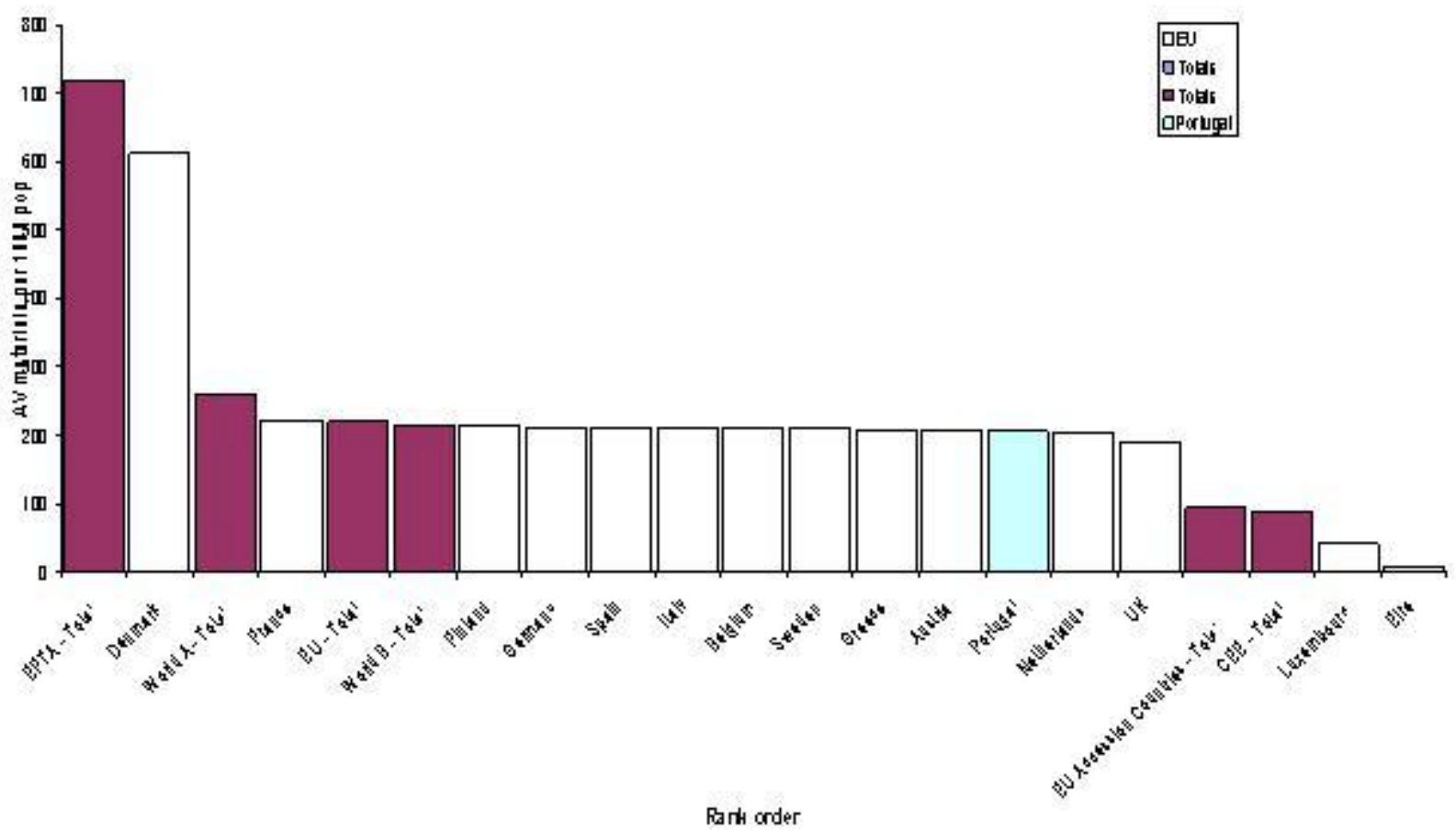

Figura 3 - Histograma de tamanho de coleções

Fonte - pesquisa em <http://www.libecon.org >

A comparação é objetiva e ajuda a entender resultados e melhorar práticas dos serviços prestados pela biblioteca.

\subsection{Equinox}

O Equinox também é um site com indicadores padronizados para bibliotecas com o objetivo inicial de padronizar as bibliotecas, perdendo por isso, a singularidade cultural de cada país. Este projeto pode servir para tornar conhecidos os indicadores de qualidade utilizados internacionalmente.

O Equinox desenvolveu os seguintes indicadores:

- percentagem de população que utiliza o serviço eletrônico de informação;

- número de sessões de cada serviço eletrônico de informação por membro da população;

- número de sessões remotas dos serviços eletrônicos de informação por membro de população a ser servida;

- número de documentos a serem consultados por sessão em cada serviço eletrônico da biblioteca;

- custo por sessão para cada serviço eletrônico da biblioteca;

- custo por documento consultado por cada serviço eletrônico da biblioteca; 
- percentagem de pesquisas de informação submetidas eletronicamente;

- média de utilização dos terminais informáticos da biblioteca;

- número de horas disponíveis, dos terminais da biblioteca, por utilizador;

- percentagem das sessões rejeitadas em função das sessões realizadas;

- percentagem das aquisições em serviços eletrônicos de informação em função do total das aquisições;

- número de presenças nas ações de formação sobre serviço eletrônico de informação pela população total a servir;

- pessoal da biblioteca envolvido, na gestão e aquisição dos serviços eletrônicos;

- satisfação do utilizador em relação aos serviços eletrônicos da Biblioteca.

É interessante que os indicadores que se esteja buscando melhorar estejam evidentes na biblioteca e no dia-a-dia do bibliotecário, para que seus usuários tenham conhecimento do ambiente proativo em que buscam as informações. Somente a inquietação na busca de melhores práticas indicará o potencial de melhoria e as perspectivas de sucesso da biblioteca.

\section{MELHORIA CONTÍNUA E O SENSEMAKING}

Expostos a um grande fluxo de informação, hoje se vive em um ambiente de constante mudança e, como conseqüência, em um ambiente sempre atualizado de necessidades. A constante busca pela melhor maneira de realizar tarefas, de prestar um serviço de maior qualidade e de atender as necessidades de informação, remete a um conceito concebido em 1986 por Massaki Imai, em seu livro Kaizen: The Key to Japan's Competitive Success, chamado de "melhoria contínua" ou Kaizen, uma palavra de origem japonesa onde "Kal" significa mudança e "Zen" significa bom, ou seja, mudança para meIhor (IMAI, 1986).

Trazendo esta realidade para a biblioteca, é possível imaginar um espaço onde se busca informação, ou seja, um local onde quem não se atualiza está fadado a não prestar um bom serviço e não atender às necessidades de seus usuários. O foco desta seção está justamente em "atender necessidades". 
Brenda Dervin, na década de 80, desenvolveu um conceito para identificar as necessidades dos usuários de determinado sistema e o tratou por sensemaking, que consiste em expor a maior parte, ou a totalidade, dos gaps ou lacunas existentes entre o usuário e um sistema (DERVIN, 1983). Apesar de seus quase 30 anos, o sensemaking remete a um trabalho desafiante para todos os gestores de sistemas que envolvem a informação. A teoria de Dervin (1983) admite que a busca e o uso da informação são atividades necessárias à criação do sentido individual do ser humano. A informação não é algo que exista sozinha, ou seja externa ao ser humano, ao contrário, é um produto da observação humana sobre si própria e sobre os outros, lembrando o intra-psicológico e o interpsicológico. O objetivo da autora foi desenvolver um modelo que focasse na maneira como os indivíduos usam as informações, externas e internas, para desenvolver sua noção de realidade e conduzir seu comportamento, como o nome diz, utilizar a informação para "criar sentido".

No modelo sensemaking é fundamental entender que freqüentemente o usuário se deparará com uma lacuna, ou problema, e neste momento iniciará um processo de: interpretar e transpor o problema; utilizar uma estratégia para abordar e para solucionar o problema; obter um feedback do que foi feito; e reiniciar uma nova fase de busca da informação. O sensemaking então é um modelo que dispõe sua abordagem de maneira a criar um movimento no usuário do sistema, transformando dúvida em ação.

Assim sendo, não fica difícil vislumbrar uma situação onde esteja envolvido o sensemaking. Numa simples conversação, por exemplo, existe a troca de argumentos e, por conseqüência, uma reestruturação na maneira de ver as coisas. Isso faz os interlocutores mais preparados para uma próxima discussão, logo, o assunto passa a criar significado na maneira destes verem o mundo. Partindo do principio que essa mudança existe, assume-se que o sensemaking é então influenciado pelos pontos de vista de cada indivíduo e começa a desenvolver um sentido mais amplo do que está ocorrendo, podendo assim as idéias ser relacionadas e associadas em redes de significado.

O sensemaking não é então uma maneira de interpretar uma situação e sim uma maneira de ajudar o usuário da informação a entender esta situação. Quando se assume a interpretação de alguma coisa, pode-se dizer que esta realidade está ali para ser descoberta, mas na verdade ela está ali para ser inventada. Quando então se trata de sistemas de informação, não adianta apenas mostrar o resultado das análises, fruto de uma realidade individual, para o usuário; tem-se sim que permitir a ele criar a sua realidade diante daquela lacuna ou problema. O próprio gestor do sistema teve experiências dife- 
rentes dos usuários e pode tentar trazer somente a sua realidade para o sistema, mas isso seria uma grave negligência.

O sensemaking não pode ser visto então como um formulário para conhecer o sujeito, mas sim como uma ferramenta de apoio para tornar os sistemas de informação mais flexíveis, acessíveis e próximos do usuário, visando o atendimento de suas necessidades no processo de busca da informação. Sua maior relevância está em considerar que os usuários têm necessidades diferentes por terem vivenciado experiências diferentes, e o gestor deste sistema deve saber que tantas são as lacunas possíveis em um sistema, quantas as possibilidades de reduzi-las para o usuário.

\section{CONSIDERAÇÕES FINAIS}

O ambiente de trabalho das bibliotecas mudou rapidamente, vindo a Internet e as TICs a imprimirem uma dinâmica diferente na gestão de serviços e produtos. Nesse contexto, o bibliotecário tem que laborar e adaptar a biblioteca a uma nova realidade de inovação, estratégia e previsão de outros caminhos a percorrer em interação com o usuário identificando e atendendo as suas necessidades. Portanto, é importante ao bibliotecário interpretar o significado das mudanças externas do ambiente, propiciando um diálogo com os usuários que conduza a biblioteca à inovação, à construção de conhecimento e à tomada de decisão. E isso só é possível através de um processo resultante de interação e compartilhamento com a comunidade, na identificação e no atendimento das suas necessidades, e por meio da oferta de serviços de qualidade.

A busca do melhor desempenho possível é uma prática muito saudável para qualquer tipo de gestão ou negócio, pois demonstra preocupação com a sobrevivência e com a longevidade do mesmo. Ter em mente este conceito e trabalhar com a abordagem do sensemaking dá uma amplitude ímpar na condução de qualquer negócio, pois permite ao gestor estar sempre buscando a melhoria com foco numa gestão participativa centrada no usuário. Estes dois métodos visam então um alvo comum: a prestação de um serviço cada vez mais próximo da necessidade do usuário. 


\title{
REFERÊNCIAS
}

CHOO, Chun Wei. A Organização do conhecimento. São Paulo: SENAC, 2006.

DERVIN, Brenda. An overview of Sense-making research: Concepts, methods and results to date. In: International Communication Association Annual meeting, Dallas, Texas, USA, 1983. Disponível em: <http://faculty.washington.edu/wpratt/MEBI598/Methods/An\% 20Overview\%20of\%20SenseMaking\%20Research\%201983a.htm>. Acesso em: 03 set. 2010.

GROGAN, Denis. A prática do serviço de referência. Brasília: Briquet de Lemos/Livros, 2001.

IMAI, Masaaki. Kaizen: The Key to Japan's Competitive Success. New York: Random House, 1986.

LIRA, Waleska Silveira; CANDIDO, Gesinaldo Ataíde; ARAUJO, Geraldo Maciel; BARROS, Marcelo Alves. Processo de decisão do uso da informação. Perspectivas em Ciência da Informação, Belo Horizonte, v.12, n.2, p.64-80, maio/ago.2007. Disponível em: <http://www2.eci.ufmg.br/pcionline/viewarticle.php?id=543>. Acesso em: 03 set. 2010.

MASLOW, Abraham H. Motivation and personality. New York: Harper \& Row, 1970.

MELO, Luiza Baptista. Estatísticas e avaliação da qualidade e do desempenho em bibliotecas e serviços de informação: Investigações Recentes e Novos Projectos. Disponível em: <http://badinfo.apbad.pt/congresso8/com20.pdf>. Acesso em: 03 set. 2010.

VERGUEIRO, Waldomiro. Qualidade em serviços de informação. São Paulo: Arte \& Ciência, 2002.

\section{Title}

A service suggestion to school library users' needs of information through benchmarking and sensemaking

\begin{abstract}
This article presents a suggestion of discussion about information services' quality, knowledge building focused in the user and considerations about the use of information comparison regarding the search for excellence. It approaches search procedures, handling, usage and comparison of information in order to verify services' quality provided to library users, focusing on benchmarking and sensemaking use with the aim of qualifying library services and satisfying users' needs in their search for information. It is characterized as a contribution to the librarians, providing a reflection upon the need for new attitudes which include the interaction with users in process checking for information search within the library, in meaning interpretation, knowledge building and decision making so as to build qualified and accessible information services to everyone.
\end{abstract}

\section{Keywords}

Information Search. Quality in Information Services. Library Management. 


\section{Título}

Una propuesta de asistencia a las necesidades de información de los usuarios de la biblioteca escolar por medio del benchmarking y del sensemaking

\section{Resumen}

Este artículo presenta una propuesta de discusión a respecto de la calidad en los servicios de información, la construcción del conocimiento centrado en el usuario y las consideraciones acerca de la utilización de la comparación de informaciones en la búsqueda por excelencia. Describe los procesos de búsqueda, procesamiento, uso y comparación de informaciones para el control de la calidad de los servicios prestados a los usuarios de las bibliotecas, centrándose en la aplicación de benchmarking y del sensemaking para calificar los servicios de las bibliotecas y atender a los usuarios en sus necesidades de búsqueda de la información. Se caracteriza como una contribución a los bibliotecarios, posibilitando una reflexión con respecto a la necesidad de nuevas actitudes, incluyendo la interacción con los usuarios en la verificación del proceso de búsqueda de información dentro de la biblioteca, en la interpretación del sentido, en la construcción de conocimientos y en la toma de decisiones, con el fin de volver los servicios de información calificados y accesibles para todos.

\section{Palabras clave}

Búsqueda de la Información. Calidade en los Servicios de Información. Gestión de Bibliotecas.

Recebido em: 30.01.2010

Aceito em: 15.09.2010 